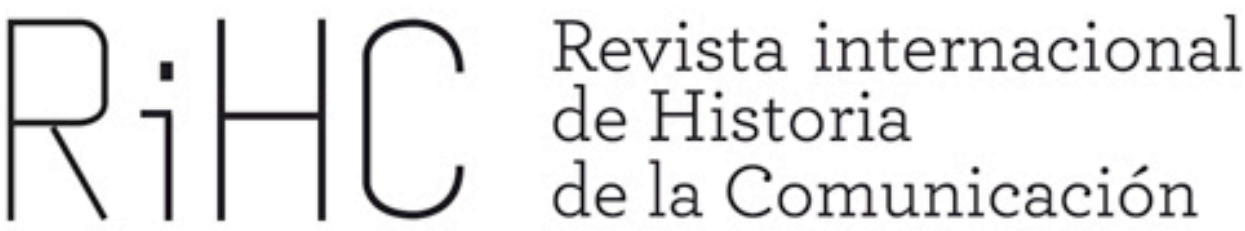

\title{
EL INCIDENTE DARANAS- SOLMS: LA DISPUTA POR LA POLÍTICA INFORMATIVA FRANQUISTA EN PARÍS EN 1942
}

Daranas-Solms Incident's: Dispute by the francoist information policy in Paris in 1942

DOI: http://dx.doi.org/10.12795/RiHC.2017.i08.06

Antonio César MORENO CANTANO

Universidad Complutense de Madrid antoniomorenocantano@hotmail.com

Resumen: En 1942, en el punto álgido de la Segunda Guerra Mundial, la capital francesa fue testigo (como en otras tantas ocasiones, por ejemplo durante la Guerra Civil española) de los enfrentamientos por cuestiones de competencias entre diferentes 
periodistas españoles, en este caso Mariano Daranas, Felipe de Solms y Bartolomé Calderón Fonte. Bajo la acusación de "ladrón y judio" se abrió un proceso judicial en París, incoado por el Tribunal de Honor de la Prensa Extranjera, que sacó a la luz las tensiones y disputas internas por el control de la propaganda y prensa franquista en el exterior. A partir de fuentes archivísticas inéditas analizaremos este incidente, contribuyendo a un mejor conocimiento del funcionamiento de la maquinaria propagandística española en tiempo de guerra.

Palabras clave: Prensa, Segunda Guerra Mundial, Francia de Vichy, España franquista, lucha propagandística.

Abstract: In 1942, at the height of World War II, the French capital was witness (as on so many occasions, for example during the Spanish Civil War) the confrontations for competition issues between different Spanish journalists, in this case Mariano Daranas ,Felipe de Solms and Bartolomé Calderón Fonte. Under the accusation of "thief and jew" a judicial process was opened in Paris, initiated by the Court of Honor of the Foreign Press, which brought to light internal tensions and disputes over the control of the Francoist propaganda and press abroad. From unpublished archival sources we will analyze this incident, contributing to a better knowledge of the operation of the Spanish propagandistic machinery in time of war.

Keywords: Press, Second World War, Vichy's France, Francoist Spain, propaganda fight

\section{Introducción: la lucha por las competencias propagandísticas en el extranjero}

En plena Guerra Civil, el ministro de Exteriores del bando franquista, Francisco GómezJordana, se quejaba de la falta de unidad que tenía lugar en las Misiones diplomáticas exteriores, en parte por la desconexión existente ${ }^{1}$. Este panorama provocó que en importantes capitales europeas, como París, "nuestra propaganda, por medio de la Prensa, es deficientísima" ${ }^{2}$. La situación no mejoró tras la finalización del conflicto español, ni mucho menos. Durante la Segunda Guerra Mundial, sendos proyectos sobre el posible control de la propaganda y prensa franquistas en el extranjero condujo a un duro choque entre el Ministerio de Exteriores y la Vicesecretaría de Educación Popular (VSEP), especie de "Ministerio de la Propaganda" en manos de FET y de las JONS. Nos referimos, en primer lugar, al borrador de decreto que Ramón

\footnotetext{
${ }^{1}$ Archivo del Ministerio de Asuntos Exteriores, Archivo Renovado, caja 830, expediente 143 (en adelante, se abreviará AMAE, R. 830/143). "Despacho del Ministerio de Asuntos Exteriores al Ministro de Industria y Comercioa, Juan Antonio Suanzes", 26 de septiembre de 1938.

${ }^{2}$ AMAE, R. 830/152. "Nombramiento de Agregados de Prensa", 9 de septiembre de 1938.
} 
Garriga (corresponsal de la Agencia EFE en Berlín), redactó -por mandato del máximo responsable de la cartera de Exteriores, Ramón Serrano Suñer- en el verano de 1942 para que la Prensa y Propaganda en el extranjero dependiese de él. En respuesta, el secretario general del Partido, José Luis de Arrese, enconado adversario del "cuñadísimo", reclamó por esas mismas fechas que fuese la referida Vicesecretaría la que tuviese la facultad de nombrar a los agregados y jefes de Oficinas de Prensa adscritos a las Embajadas ${ }^{3}$. Franco, en un juego de contrapesos políticos perfectamente orquestado, rechazó ambas propuestas.

Descendiendo un escalafón en este nivel de enfrentamientos, observamos que las tensiones se produjeron no solo entre los máximos jerarcas de estos organismos, sino que fueron muy numerosas y graves entre sus subalternos. A modo de síntesis podemos citar las discrepancias entre el agregado de Prensa, el falangista Ángel Alcázar de Velasco y los funcionarios de la Embajada en Londres ${ }^{4}$; el rechazo de Falange y del propio agregado, José Ignacio Ramos, al nombramiento de Antonio Magaz y Pers como embajador en Buenos Aires, cuya actividad fue calificada de "pésima gestión" agregado de Prensa, el falangista Javier Gaytán de Ayala, que fue acusado de malversar los fondos de la Oficina de Prensa en Washington (LÓPEZ ZAPICO, 2013: 211-239). Incluso miembros de Falange, como los agregados en Lisboa y Bucarest en esos años, Javier Martínez de Bedoya y Juan Manuel de la Aldea, fueron intensamente atacados por la también "azul" VSEP 6 . Muchos de estas tensiones, al fin y al cabo, son reflejo de las diferencias ideológicas y políticas que se generaron entre las diferencias "burocracrías del régimen" desde 1937. Los medios de comunicación de masas -en palabras de Eduardo González Calleja- se transformaron "en caballo de batalla preferente para los grupos políticos en un sorda lucha por el poder" (GONZÁLEZ CALLEJA, 1990: 495). Estas rivalidades ponían a la vista, "la impotencia y desorganización de Falange... que en vez de disminuir se había extendido desde el final de la guerra" (CAZORLA, 2000: 26), no solo en el interior del país sino principalmente en el exterior.

\footnotetext{
${ }^{3}$ Archivo de la Presidencia del Gobierno, leg. 33/5.1. "Proyecto de Ley elaborado por el Ministerio de Asuntos Exteriores sobre la Prensa y Propaganda" y "Reglamentación que se propone por la Vicesecretaría de Educación Popular", 1942.

${ }^{4}$ Archivo General de la Administración (en adelante, AGA), Cultura, caja 264. "Notas sobre la situación de la Delegación de Prensa en Inglaterra", 1941.

${ }^{5}$ AGA, Presidencia, Secretaría General del Movimiento, caja 18950. "Carta de José Ignacio Ramos al camarada jefe, Genaro Riestra, secretario nacional de la Delegación Nacional del Servicio Exterior de Falange", 19 de noviembre de 1941.

${ }^{6}$ AGA, Cultura, cajas 1107 y 1553. "Despacho de la Delegación Nacional de Prensa al Sr. Agregado de Prensa en Lisboa", 7 de julio de 1944, y "Carta del Delegado Nacional de Prensa, Juan Aparicio, al Sr. Agregado de Prensa en Bucarest", 14 de diciembre de 1942.
} 
Francia fue el mejor exponente de estas luchas de competencias, que vivieron con la disputa entre los periodistas Mariano Daranas, Felipe de Solms y Bartolomé Calderón Fonte uno de sus episodios más relevantes y llamativos. En suelo galo, desde el inicio de la Guerra Civil, operaron simultáneamente varios organismos propagandísticos englobados bajo la égida de la coalición insurgente (carlistas, falangistas, monárquicos, católicos, los miembros de la Lliga Catalana o el propio Estado). Con el decreto de unificación las diferencias no desaparecieron, al contrario, se avivaron con mayor fuerza y se dieron intensísimos encontronazos entre los representantes de la España Nacional, en concreto entre Quiñones de León y los antiguos miembros de la Lliga, cuya anterior autonomía y origen catalán no eran del agrado de las autoridades españolas (RIQUER, 1999: 99-110). De igual manera, los responsables de FET y de las JONS en Francia -Federico Velilla (del que nos ocuparemos con más detalle en páginas posteriores) y Antonio Hernández Soriano- no estaban dispuestos a ceder el menor ápice de terreno al estamento diplomático ni a los nuevos responsables de la propaganda estatal, que eran ni más ni menos que el antiguo equipo de Francesc Cambó en París, capitaneados por el mallorquín Joan Estelrich (MASSOT I MUNTANER, 1998: 65-198). Incluso dentro de las propias filas falangistas se vertieron continuas acusaciones de inoperancia, dejando traslucir un deseo de prosperar a nivel personal denigrando al "compañero" y reafirmando, de cara a los altos jerarcas del Partido, el valor propio (BERMEJO, 1996:229-235). Este género de dificultades tuvieron su continuación en la contienda mundial, pues el agregado de Prensa, Antonio Zuloaga, fue constantemente atacado por Federico Velilla y la VSEP, más favorable a posicionar a algún falangista cerca de la Embajada española en Francia. (SUÁREZ-ZULOAGA, 2012: 121-148). En estas luchas de suspicacias también tuvo un protagonismo destacado uno de nuestros protagonistas, Felipe de Solms, que en un informe de 1941 remitido a sus superiores en Madrid, arremetía contra el propio Velilla por el rumbo dado a Falange en tierras francesas, temeroso de lograr "una verdadera Propaganda Falangista" (BERMEJO, 1998: 240).

Para entender en su totalidad la confrontación que vamos a analizar tenemos que tener muy en cuenta el contexo político en el que se enmarcó, tanto en el interior del régimen franquista como con respecto a la Francia Ocupada. En el verano de 1942, el entonces ministro de Exteriores, Serrano Suñer, veía palidecer su poder a favor de un cada vez más poderoso secretario General del Movimiento, Arrese (THOMÀS, 2001: 266-267). Aunque los dos pertenecían a Falange, hubo constantes choques en diferentes ámbitos, sobre todo, y es el que nos ocupa, en cuestiones de propaganda y prensa. Desde ambos organismos, es decir, Exteriores y la VSEP, se impulsó una fuerte germanofilia informativa que debía conjugarse con las presiones ejercidas por el cuerpo diplomático angloamericano en la Península Ibérica, lo que no era tarea fácil (MORENO CANTANO, 2016). Lo que menos necesitaban, en ese momento, era que diferentes periodistas españoles dirimiesen sus diferencias en público, bajo acusaciones de índole racial o de falta de apoyo al nazismo, pudiendo soslayar la 
confianza (ya de por si baja en Francia) del estimable socio germano. En el vecino francés, y pese a la sintonía ideológica que impulsaba principalmente el Partido desde sus diferentes órganos y medios, la Embajada alemana se había mostrado muy intransigente con los medios y representantes periodísticos franquistas. En diciembre de 1940 había sido expulsado de la Francia Ocupada el corresponsal de Ya, Francisco Lucientes, por escribir un artículo titulado "Francia evoluciona penosamente de su actual crisis", por aventurar una posible guerra civil y criticar la falta de determinación del régimen de Vichy contra el general De Gaulle. Se impedía, además, la entrada en dicha parte de Francia de gran parte de la prensa española. El agregado de Prensa de la Embajada alemana de París, Feihl, mandó la supresión de la revista Occident, impulsada por Estelrich y su equipo desde el comienzo de la Guerra Civil española ${ }^{7}$. Además, un enfrentamiento abierto entre el propio Velilla y el agregado español, Antonio Zuloaga, había llevado a la dimisión de este último a mediados de 1942 (MORENO CANTANO, 2007: 265-301).

El objetivo de esta investigación es profundizar en las complejas redes de intereses, personales y políticos, que se tejieron alrededor de la propaganda exterior franquista durante los años de contienda mundial. Pretendemos, de paso, arrojar nuevos datos que permitan profundizar en las vidas de estos periodistas y responsables propagandísticos, personajes que han pasado muy de puntillas dentro de la historiografía sobre los medios de comunicación españoles. Esta aproximación se realizará accediendo a fuentes documentales de gran valor e interés, como los fondos transferidos (y aún no catalogados) del Archivo de Exteriores al Archivo General de la Administración. En nuestra metodología predominará el enfoque cultural y político, pues la competencia exhumada, la propaganda, participaba de ambas características. Para ello tendremos muy en cuenta el contexto histórico en el que se desarrollaron los acontecimientos así como los intereses ideológicos que se encontraban detrás de muchas de las decisiones y juicios que se vertieron. Todo ello complementado con el vaciado hemerográfico de los principales diarios en los que se movieron nuestros protagonistas.

\footnotetext{
${ }^{7}$ AGA, Cultura, caja 265. "Escrito de Antonio Zuloaga al Sr. Director General de Prensa", 11 de febrero de 1941.
} 


\section{1. "Judío, ladrón, masón": Felipe de Solms y Calderón Fonte frente a Mariano Daranas}

\subsection{Breve esbozo biográfico de los implicados}

Antes de profundizar en el origen, desarrollo y consecuencias del grave suceso que tuvo lugar en París en julio de 1942 entre los tres periodistas españoles mencionados conviene realizar una aproximación a sus desconocidas figuras para entender mejor el contexto y modo de proceder en el mismo.

Mariano Daranas Romero nació en las Palmas de Gran Canaria en 1898. Siendo un adolescente comenzó a trabajar en La Gaceta de Tenerife. A los dieciséis años llegó a Madrid como corresponsal del diario La Región. En la capital entró en contacto con Manuel Delgado Barreto, destacado periodista de la época, junto al cual participó en las campañas mauristas. Figuró como militante de las Juventudes Mauristas. Ingresó en la redacción del periódico maurista La Nación, fundado por Delgado Barreto en 1916. Tras una breve etapa como crítico teatral (1918-1919) pasó a El Debate, dirigido por Ángel Herrera, que en 1924 le nombró redactor político y en 1928 corresponsal en París. Dos años después comenzó a desempeñar la corresponsalía de $A B C$ en la capital francesa. Colaboró con la Dictadura de Primo de Rivera, con el que tenía una estrecha amistad. En 1933 conoció al empresario mallorquían Juan March, con el que mantuvo un intenso contacto a lo largo de toda su vida. Durante la Guerra Civil no estuvo movilizado debido a su edad. Tomó parte, pese a todo, en actos de propaganda y adhesión a la causa nacional-sindicalista en el sector Carabanchel-Leganés ${ }^{8}$. Durante la mayor parte del conflicto español, desde su corresponsalía en París, impulsó diferentes campañas entre la prensa de derechas para apoyar la causa franquista, lo que le valió la admiración entre sus compañeros de profesión: "si se fuera a medir en cifras comparativas la equivalencia de este esfuerzo, podría decirse que Daranas ha mandado a España muchos miles de hombres y muchos millones de pesetas" ${ }^{\prime 9}$. Su "carácter temperamental y, por así decirlo, excesivamente violento" (como se refljeó en informes posteriores de sus superiores), le llevó a denunciar públicamente al afamado escritor Manuel Machado, como "funcionario y periodista del Frente Popular", por una entrevista que había concedido a la revista francesa Comedia, en la que -según su parecer- se había mostrado poco entusiasta con "la revolución nacionalista" (D’ORS, 2000: 158-163). Cualquier acto propagandístico del Gobierno

\footnotetext{
${ }^{8}$ AGA, Presidencia, Registro Oficial de Periodistas, caja 13866, expediente 567, Mariano Daranas Romero; y $A B C$, "Fallece en Madrid el veterano periodista Mariano Daranas", 28 de abril de 1994.

9La Prensa. Diario de la Mañana (Santa Cruz de Tenerife), "La labor de un canario en París", por Antonio Marti, 9 de septiembre de 1936.
} 
republicano en Francia encontró rápidamente contestación desde sus columnas, como fue la participación en la Exposición Internacional de París en la primavera de 1937 (ANDRÉS GALLEGO, PAZOS y ANDRÉS, 2011: 41-72): “¿a quién convencerán los residenciados de Valencia y Barcelona de que en la España roja rige un Estado o sombra de él?"10. La entrada en guerra de Francia en septiembre de 1939 le dio pie para atacar la posición antipatriótica del Partido comunista, sin valorar la agresión germana en Polonia: "La III Internacional es un instrumento de antipatriotismo perfecto, inmejorable, más dañino aún que el antipatriotismo anarquista, porque labora y se agita a favor de una patria extranjera"11 ${ }^{11}$ Y acusaba a los políticos franceses de haber tolerado la existencia de dicho partido en los años precedentes, favoreciendo con ello "la bolchevización de Europa" y dando motivos para la lucha de Hitler contra el comunismo a nivel internacional ${ }^{12}$. Las condiciones del armisticio firmado con el Tercer Reich en junio de 1940 fueron calificadas (en un claro gesto de germanofilia) de "soportables", lejos del carácter "afrentoso o humillante" que promovía "Albión", que "tiende, principalmente, a minar y destruir desde el interior de Francia la autoridad del Gobierno que preside el mariscal Pétain" ${ }^{13}$. Pocos días antes de su discusión y pelea pública frente a sus compañeros de profesión, su antisemitismo salía a relucir de la manera más violenta y agria en un duro artículo a raíz del traslado de miles de judíos al Velódromo de Invierno: "casta internacional cuya es (sic) responsabilidad de los males que afligen a Europa"14. No sorprenden, por tanto, que fuese este tipo de discursos el que utilizase para arremeter contra Felipe de Solms, al que consideraba de origen judío.

Bartolomé Calderón Fonte era originario de Barcelona. Nació en 1886 y en 1910 se incorporó a las Juventudes del Partido Radical de Lerroux ("Juventud Escolar Republicana"), en concreto al grupo conocido como La Kabila, ya que calificaba a las tribus rifeñas como "grupos salvajes" y ellos se consideraban como "bárbaros" que querían destruir la sociedad existente, monárquica y con grandes desigualdades, sustituyéndola por una República Social. Fueron perseguidos y encarcelados por las autoridades catalanas, no tanto por lo que hicieron sino por lo que represantaban: "el mitón del joven bárbaro incendiario y violador de novicias". Por esa razón, junto con algunos de sus compañeros se exilió a Francia (CULLA, 2005: 51-67), ya que en 1914 fue procesado por el Juzgado de Instrucción de Barcelona por excitación a la

\footnotetext{
${ }^{10} A B C$, "El Frente Popular español en la Exposición de París", por Mariano Daranas, 7 de marzo de 1937.

${ }^{11} A B C$, "El partido comunista francés, a pesar de su actitud antipatriótica, sigue en pie y organizado", por Mariano Daranas, 5 de septiembre de 1939.

${ }^{12}$ ABC, "El enemigo", por Mariano Daranas, 29 de septiembre de 1939.

${ }^{13} A B C$, "Homenaje a España. La intriga inglesa y la huida de los rojos españoles", por Mariano Daranas, 27 de junio de 1940.

${ }^{14} A B C$, "La separación de los judíos", por Mariano Daranas, 21 de julio de 1942.
} 
sedición ${ }^{15}$. En París abrió un negocio de calzado y en 1927 ingresó en la Logia masónica L'Union Latine (su nombre aparecía en la famosa obra La Grande Loge de France, constitution et réglements, liste des membres) con el objetivo de encontrar nueva clientela merced a los excelentes contactos políticos y económicos que mantenían muchos de sus miembros. Semanas después la abandonó ya que "experimentó la sensación de que no correspondía a la secta, no solo a sus aspiraciones comerciales sino a sus sentimientos y educación". Desde entonces expresó que "la masonería es sinónimo de judaismo con su espíritu materialista y mesiánico, engendrador de guerras y de luchas fratricidas" ${ }^{16}$. En 1927 se convirtió en ciudadano francés. Con el advenimiento de la República regresó a Madrid, donde obtuvo -en una de las facetas más sombrías y pendiente de profundizar en futuras investigaciones- una signación mensual permanente en los fondos secretos del Ministerio del Interior. En 1936, con el inicio de la Guerra Civil, salió de territorio republicano por Alicante gracias a la ayuda de la Embajada francesa, ya que su esposa era de esa nacionalidad. De inmediato pasó a colaborar -seguramente por afinilidad ideológica y, sobre todo, territorial- con los catalanistas de Cambó, que se agruparon en busca de apoyos a Franco alrededor de la Agence d'Information Espagnole, que comenzó sus actividades en París en 1937. Incluso se apunta que fue el responsable de la primera Falange clandestina en suelo francés, permaneciendo en ella (ya bajo la denominación de Subdelegación de Prensa y Propaganda) hasta 1939. Mantuvo una excelente relación con el agregado de Prensa de la Embajada española, Antonio Zuloaga, que destacó "sus brillantes dotes de Periodista, avaloradas por un patriotismo ferviente y una confianza, que no se desmintió nunca, a favor de la Causa Nacional” ${ }^{\prime 7}$. Fue ante este personaje donde presentó, a finales de 1940, su declaración-retractación por su pasado masónico. Pero esta exculpación, como analizaremos a raíz de su controversia con Daranas, no fue suficiente para limpiar su pasado y garantizar su porvenir.

De Felipe de Solms Davids apenas tenemos datos. Nació en Madrid en 1916, siendo educado en Francia, donde cursó el Bachillerato y estudios de Finanzas. Su padre, Guillermo W. Solms, fue un próspero inversor, presidente de la sociedad "SantánderMediterráneo, Compañía del Ferrocárril Estratégico Santander-Burgos-Soria-Calatayud, S.A". Mantuvo estrechos contactos con la monarquía y la Dictadura de Primo de Rivera. Regresando a Felipe, sabemos que en abril de 1939 fue nombrado alférez provisional de Infanteria en la Academia Militar de Granada y destinado al Cuerpo del Ejército de Castilla ${ }^{18}$. Más adelante aparecía como Jefe de Prensa de la Falange en París

\footnotetext{
${ }^{15}$ AGA, Presidencia, Registro Oficial de Periodistas, caja 13912, expediente 2004.

${ }^{16}$ Centro Documental de la Memoria Histórica (en adelante, CDMH), Tribunal Especial de Represión de la Masonería y el Comunismo (en adelante, TERMC), sumario n.o 4541. "Declaración-retractación de Bartolomé Calderón Fonte", 15 de octubre de 1940.

${ }^{17} \mathrm{CDMH}, \mathrm{TERMC}$, sumario n. 4541. “Certificado del Registro Oficial de Periodistas”, 1941.

${ }^{18}$ Boletín Oficial del Estado, "Subsecretaría del Ejército. Ascensos y condecoraciones", 8 de abril de 1939, p. 2006.
} 
y colaborador del Diario de Barcelona. A partir de la ocupación alemana de Francia empezó a colaborar con la Embajada germana, en concreto dando charlas en la Emisora de París. También realizó algunos trabajos en medios como Les Nouveaux Temps y Toute la Vie ${ }^{19}$.



\subsection{1 .2 El origen del conflicto}

A finales de 1942 Juan Aparicio recibía, en la mesa de su despacho de la Delegación Nacional de Prensa, un conjunto de informes que describían un panorama desastroso de la acción periodistas españoles en la capital francesa. Acusaciones, reproches, envidias... no eran las mejores armas para promocionar a la Nueva España en el exterior. Abría el telón el corresponsal de El Correo Catalán, Marcial Retuerto (autor en 1941 de la famosa obra Como viven los españoles en París), que -según fuentes procedentes de la Embajada alemana y del Sindicato de la Prensa Extranjerareprochaba a Felipe de Solms y Bartolomé Calderón el hecho de autonombrarse como los únicos periodistas autorizados oficialmente por el Estado español para ejercer su profesión en París. Aprovechaba esta argumentación para plantear dudas morales

\footnotetext{
${ }^{19}$ AGA, Cultura, caja 233. "Interrogatorio a Felipe de Solms", septiembre de 1942.
} 
sobre la actividad de dichos personajes. Sobre Solms señalaba que "existe muy arraigada la creencia en los medios oficiales de esta ciudad de que su solvencia intelectual es nula y de que, moralmente, deja mucho que desear"; y Calderón Fonte era "un hombre que ha renegado de la nacionalidad española... que se halla inscrito en las logias francmasónicas de París con un grado bastante elevado, que ha combatido a la Falange de París de modo lamentable..." ${ }^{20}$. Detrás de estas graves imputaciones salían a relucir viejas rencillas, pues Retuerto enunciaba también la oposición que había recibido de ellos mientras se empleaba en El Hogar Español, el órgano de la colonia española en Francia. Solo un día después, el periodista vasco Javier Esteban Indart, se expresaba en términos muy similares: "el hecho que hasta aquí estos dos señores hayan podido ejercer la profesión nos cubría de vergüenza. Pero después de la actitud que han adoptado... la atmósfera es irrespirable, verdaderamente asfixiante" ${ }^{21}$. Esta opinión se reforzaba con la del periodista Murga (apodado "El Marqués de Alcázar"), responsable de los servicios europeos de La Prensa de Buenos Aires y miembro del Sindicato de la Prensa Extranjera en París, que ponía el acento en el "escándalo y sorpresa por el descrédito que pesa sobre dichos señores"22. Otro escrito hacía aparecer ya en escena al corresponsal de $A B C$, Daranas, que en una charla en un círculo restringido formado por reconocidos periodistas extranjeros y diplomáticos alemanes y franceses, se mostraba "preocupado por dificultades de carácter doméstico". Esta misma fuente advertía que "bien pudiera resultar que Daranas fuese víctima de alguna intriga" ${ }^{23}$. Seguramente enterado de todas estas acusaciones, Solms se comunicó con Madrid esos mismos días resaltando sus buenos contactos en París, como con el Jefe de la Prensa Extranjera alemana, Dr. Arntz; o enumerando las crónicas que tanto él como Calderon iban a publicar en destacados medios franceses en las próximas semanas ${ }^{24}$. A tenor de todos estos escritos resulta claro, con la perspectiva que ofrece el tiempo, que el incidente que tendrá lugar a finales de ese mes de julio de 1942 no ocurrió por casualidad, sino que en parte pudiese ser forzado por los actores implicados para que se dirimiese desde la VSEP qué grupo de periodistas españoles ostentaría la hegemonía de la información en Francia.

\footnotetext{
${ }^{20}$ AGA, Cultura, caja 233. "Escrito de Marcial Retuerto al Delegado Nacional de Prensa, Juan Aparicio", 27 de julio de 1942.

${ }^{21}$ AGA, Cultura, caja 233. "Escrito de Javier E. Indart al Sr. D. Juan Aparicio", 28 de julio de 1942.

${ }^{22}$ AGA, Cultura, caja 233. "Carta del Marqués de Alcázar al Sr. D. Juan Aparicio", 28 de julio de 1942.

${ }^{23}$ AGA, Cultura, caja 233. "Escrito al Sr. D. Juan Aparicio", 29 de julio de 1942.

${ }^{24}$ AGA, Cultura, caja 233. "Escrito de Felipe de Solms al camarada Juan Aparicio, Delegado Nacional de Prensa", 27 de julio de 1942.
} 


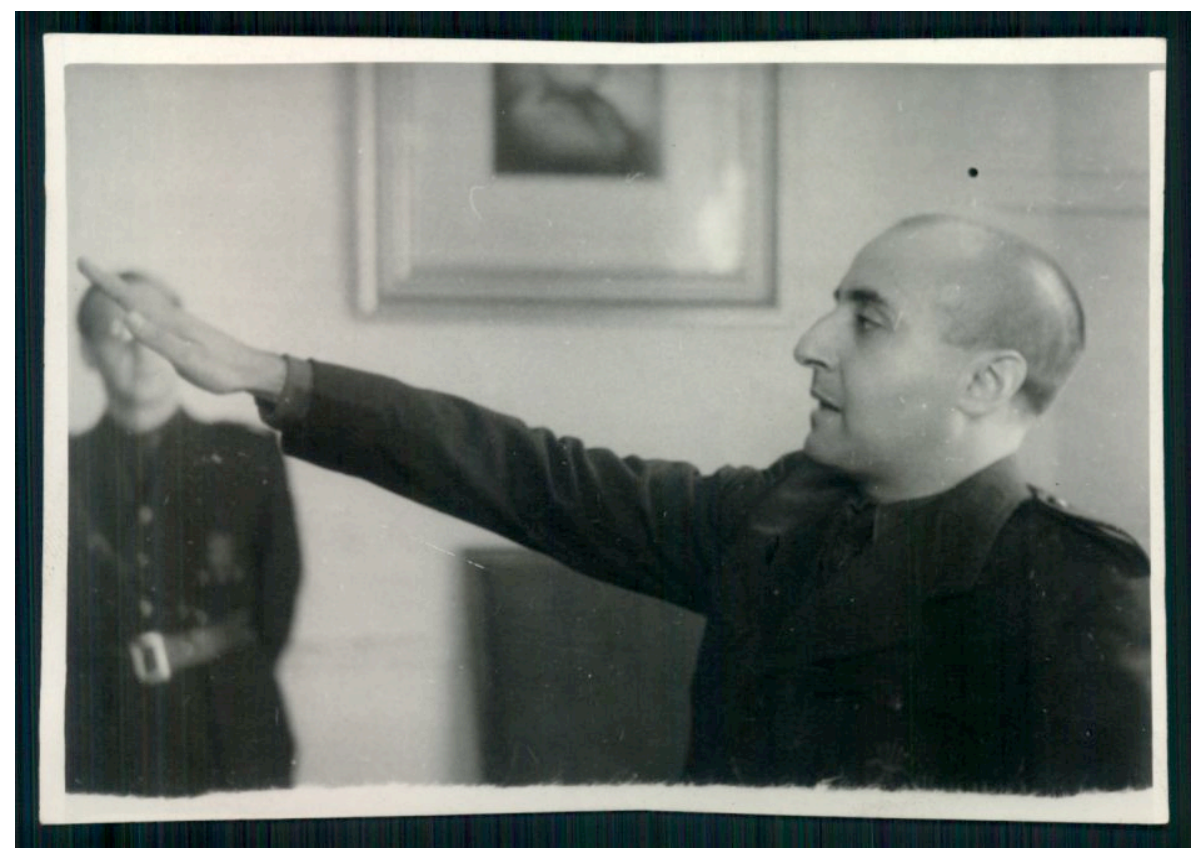

El Delegado Nacional de Prensa, Juan Aparicio, jura su cargo en 1941. Tuvo la última palabra en el conflicto de los periodistas españoles en París. Fuente: MECD, AGA, Cultura, F/02955.

\subsection{Insultos y golpes entre periodistas franquistas}

El 30 de julio toda esta tensión explotó (DOMÍNGUEZ, 2009:339-340). El lugar elegido fue la reunión semanal de la Propagandastaffel. Momentos previos a su celebración, y -según el testimonio interesado de Mariano Daranas- Solms y Calderón Fonte habían difundido entre diferentes corresponsales, como los de la agencias Prensa Mundial o París-Prensa, que el referido periodista de $A B C$ había realizado artículos muy críticos contra Hitler y eso podría impedir que lograse el salvoconducto para viajar a España. Cuando ambos se encontraron comenzaron una acolarada discusión, en la que Daranas calificó a su contrario como "judío y ladrón”. El propio Calderón fue tildado de "masón". Acto seguido, Solms y Daranas pasaron a las manos, jactándose este último incluso de esta espérpentica reacción: "le marqué repetidamente el semblante en términos que han quedado traza visible" ${ }^{25}$. Debido al calado de las acusaciones públicas que se realizaron se tomó la decisión, por parte del Sindicato de Prensa Extranjera de París, de formar un Tribunal de Honor que dirimiese este asunto. Este incidente molestó, y mucho, a Joan Estelrich, subdelegado de Prensa del Estado Español en París, que intentó que no pasase a mayores para evitar la intervención de las autoridades alemanas, ya que era un tema interno que debía ser resuelto desde Madrid por la Delegación Nacional de Prensa. Pese a las presiones del embajador, J. F. de Lequérica y del Jefe de Falange, Federico Velilla, no se pudo contener este proceso

\footnotetext{
${ }^{25}$ AGA, Cultura, caja 233. "Escrito de Mariano Daranas al Sr. D. Juan Aparicio, Delegado Nacional de Prensa", 30 de julio de 1933.
} 
debido al escándalo que había suscitado entre los periodistas extranjeros ${ }^{26}$. Para Estelrich, detrás de este triste y penoso acontecimiento se encontraba, por supuesto, "la vehemencia de Daranas" y, principalmente -y lo que era más grave- las propias autoridades alemanas y el Sindicato de Prensa Extranjera, que tendrían que haber tenido la deferencia de haber consultado a la Subdelegación de Prensa franquista en París sobre qué periodistas o no estaban autorizados para ejercer su profesión en Francia, no alimentado con falsos rumores situaciones que podían desembocar-como así sucedió- en actos de violencia y tensiones entre los propios ciudadanos españoles. Consideraba a Calderón como "hombre muy útil" al igual que Solms, "no tengo ninguna queja sobre ellos". Otro parecer muy distinto era el del cuerpo diplomático y del gremio de periodistas extranjeros, "que están al lado de Daranas y, en mayor o menor grado, contra Calderón y Solms" ${ }^{27}$. En una línea muy parecida se expresaba también Federico Velilla: "en realidad tanto el uno como el otro tienen su parte de culpa. Solms tiene la lengua muy ligera y Daranas es un exaltado que no puede tolerar que los otros escriban y medren". Aprovechaba para criticar a"esa pantomima de grupo hispanoamericano de periodistas" (Marcial Retuerto o Indart, entre otros) que rodeaban y apoyaban al corresponsal de $A B C^{28}$. Precisamente, fue esta colectividad con nombres como Klingelhoefer, del Correio da Manha (Río de Janeiro) o Acuna D’Ambrossis, de París Prensa (Montevideo)- la que firmó un escrito de solidaridad por los insultos "sufridos" por Daranas.

El 5 de agosto se formó el Tribunal de Honor que debía dirimir este episodio. Estuvo presidido por Giacomo Antonini, director de la agencia de noticias italiana Stefani y agregado de Prensa de la Embajada de Italia en Francia (FESTORAZZI, 2009), al que acompañó Solari, director de La Nouvelle Italie y el Presidente de Honor del Sindicato de Periodistas Extranjeros, Gregorio Marañón o el referido Velilla, entre otros. En el proceso verbal que se abrió, Daranas "argumentó" sus acusaciones contra Solms explicando que sus rasgos físicos y familiares eran de origen judío, como lo acreditaba el patronímico Davids de su madre. Incluso explicó que el nombre de Solms derivaba de la contracción de la palabra SALOMÓN. También le reprochaba no haber combatido en la Guerra Civil española, en una maniobra "muy judía". Le acusó también de haber estafado 200 francos y haber sustraído una máquina de escribir de la agencia Prensa Mundial. De Calderón Fonte recordó su pasado masónico, es decir, su pertenencia a la

\footnotetext{
${ }^{26}$ AGA, Cultura, caja 233. "Informe de la Subdelegación de Prensa del Estado Español en Paris al Sr. D. Juan Aparicio, Delegado Nacional de Prensa", 4 de agosto de 1942.

${ }^{27}$ AGA, Cultura, caja 233. "Informe n. 4870 de la Subdelegación de Prensa del Estado Español en París", 18 de agosto de 1942.

${ }^{28}$ AGA, Cultura, caja 233. "Escrito de Falange Española Tradicionalista y de las JONS, París, al Delegado Nacional de Prensa", 24 de agosto de 1942.
} 
logia L'Union Latine y el hecho de haber pedido la nacionalidad francesa en 1927, lo que era una señal manifiesta de su desarraigo con España ${ }^{29}$.

En su resolución, el Tribunal -cuya composición era claramente favorable a Daranasfue especialmente crítico con Solms, que se vio obligado a retractarse de sus juicios y pedirle disculpas por acusarle de atacar en sus crónicas a Hitler. El Tribunal, además, consideró que si bien Solms era "según la ley de España, católico y español", según las leyes raciales francesas y alemanas "no hay prueba de que pueda considerarse ario". Sobre el tema de los supuestos robos no se considero competente para actuar ${ }^{30}$.

\subsection{Las consecuencias del enfrentamiento}

Una vez zanjado este asunto en suelo extranjero, quedaba dirimirlo dentro de los propios órganos de la Vicesecretaría de Educación Popular. En Madrid este incidente, que había sacado a relucir las profundas rivalidades internas en el gremio propagandístico y periodístico español, no gustó nada por la mala publicidad e imagen que se hizo del régimen franquista ante dos de sus principales aliados, como era la Francia de Vichy y el Tercer Reich. Razón por la que se sometió de nuevo a un profundo interrogatorio (por parte del Jefe de Prensa Extranjera de la Delegación Nacional de Prensa, Francisco Primo Sánchez de Orovio) a Felipe de Solms. En él se analizaron las principales acusaciones vertidas por Daranas concernientes a su supuesta actividad de contrabandista, a la desaparición de doscientos francos y de una máquina de escribir, así como a su "ostentosa" vida en París. El interrogado se defendió con vehemencia de estas acusaciones y contraatacó explicando que "el Sr. Daranas es de carácter exaltado, que tiene un hijo con desviación de la columna vertebral, que acaban de operar a su mujer de gravedad" y a todo esto se le sumaba el hecho de estar rodeado por un grupo de personas de dudoso historial pasado y presente, como Marcial Retuerto, "expulsado de Falange"; José Zamora, "invertido" o Indart; "satélites que han empujado al Sr. Daranas a esta acción por envidia de los éxitos profesionales". Y concluyó su alegación recalcando que si retiró su acusación en el Tribunal de Honor fue por presiones del Cónsul de España en París, y del Jefe de Falange, Velilla ${ }^{31}$. En el Informe final de la VSEP se expuso que "son evidentes los indicios que hacen aparecer la figura del Sr. Solms envuelta en una atmósfera perjudicial al alto nombre de España y al prestigio y limpieza moral de un representante de la prensa española en el extranjero". En conclusión se le inhabilitó

\footnotetext{
${ }^{29}$ AGA, Cultura, caja 233. "Declaración de Mariano Daranas al Tribunal de Honor del Sindicato de la Prensa Extranjera", 5 de agosto de 1942.

${ }^{30}$ AGA, Cultura, caja 233. "Acta del Tribunal de Honor", 5 de agosto de 1942.

${ }^{31}$ AGA, Cultura, caja 233. "Interrogatorio a tenor del cual fue examinado el inculpado Sr. Solms", 2 de septiembre de 1942.
} 
para el ejercicio de la profesión de periodista en el extranjero y se le retiró el carnet oficial de la Delegación Nacional de Prensa ${ }^{32}$. Como respuesta a estas medidas, Solms reabrió su causa ante los tribunales de justicia franceses, aportando para ello frases publicadas por Daranas en la prensa que corroboraban -según su criterio- su falta de adhesión y simpatía hacia el nazismo. Una de las sentencias más controvertidas es la que apareció en $A B C$ el 13 de agosto de 1939: "Es una monstruosidad que el Tercer Reich haya negado y arruinado a su población judía"33. A primera vista no hay duda que se trata de un ataque a la política racial germana, pero como toda frase-más en el mundo periodístico- pierde su significación clara si no aparece el marco o contexto general en el que se insertó. El resultado no deja lugar a dudas de la manipulación perpetrada por Solms, ya que la intención de Daranas no era otra que arremeter contra Londres, Washington y Moscú, cuyas acciones en el exterior siempre se justificaban mientras que las de la Alemania nazi eran duramente criticadas:

Es una monstruosidad que el Tercer Reich haya negado y arruinado su población judía, más las matanzas de árabes en Palestina apenas trascienden al público francés o al público británico. Los checos suscitan un movimiento universal de conmiseración y simpatía; pero a los portorriqueños, sañuda y sistemáticamente oprimidos a partir de fines de siglo por el imperialismo yanqui, que les parta el rayo de su hispanidad ${ }^{34}$

Además, apelando a diferentes ordenanzas alemanas y galas, explicaba a Juan Aparicio que "son considerados como no judíos todos aquellos que siendo de religión católica, así como sus padres desde antes del principio de la guerra tienen dos abuelos católicos sobre los cuatro que cada uno tiene ${ }^{\prime 35}$. Daranas se hizo eco rápidamente de estos planteamientos y se puso en contacto con el delegado Nacional de Prensa, al que recordó su "admiración por la Alemania Nacional-Socialista y concretamente por el Canciller Hitler" y advirtió que el referido Solms invocaba constantemente que actuaba bajo el paraguas de la VSEP" ${ }^{36}$ La respuesta fue contundente: "el citado Sr. Solms no tiene ya ninguna relación de dependencia con esta Delegación Nacional de Prensa". Y, aunque no aparecía reflejado en dicha contestación, se empujó a Daranas a zanjar de una vez por todas el asunto, lo que explica que remitiese unos días después una carta en la cual expresaba que "no he tenido intención ninguna de inferirle daño moral o material, cualesquiera que fuera el lenguaje a que me llevó, un momento de

\footnotetext{
32 AGA, Cultura, caja 233. "Informe del camarada Francisco Primo Sánchez de Orovio", 3 de septiembre de 1942.

${ }^{33}$ AGA, Cultura, caja 233. "Alegato de Solms al Presidente del Tribunal”, 14 de septiembre de 1942.

${ }^{34} A B C$, "ABC en París. En el Báltico", por Mariano Daranas, 13 de agosto de 1939. La cursiva es nuestra.

${ }^{35}$ AGA, Cultura, caja 233. "Carta de Felipe de Solms al Delegado Nacional de Prensa”, 19 de septiembre de 1942.

${ }^{36}$ AGA, Cultura, caja 233. "Escrito de Mariano Daranas al Sr. D. Juan Aparicio", 12 de octubre de 1942.
} 
arrebato $^{\prime 37}$. Solms se vio obligado a aceptar las disculpas y a retirar su querella del Tribunal. No tenía más opción, el embajador Lequerica le había amenazado con expulsarlo de Francia en caso contrario, pues era un asunto "muy perjudicial para los intereses de la colonia"38. Es interesante observar cómo se enfriaron las relaciones entre el ex corresponsal y el Delegado Nacional de Prensa a lo largo de los meses. El simple análisis de los saludos y despedidas de sus informes es muy revelador en este aspecto y complementa todos los datos que se han aportado a lo largo de la investigación. Antes de su choque con Daranas, Solms cerraba sus misivas a Juan Aparicio con la frase "con un saludo brazo en alto se despide de ti tu subordinado y amigo agradecido". En cambio, una vez apartado de su profesión y tras el "aviso" del cuerpo diplomático, aparecía un más aséptico "te saluda con todo respeto..."

Más trágico fue el destino de Bartolomé Calderón Fonte a partir del cruce de insultos y reproches con el periodista Daranas. En octubre de ese año el Juez de Instrucción n. 2 del Tribunal Especial para la Represión de la Masonería y el Comunismo le abrió un sumario (n.o 1289 y 4541) por haber pertenecido a la logía L'Unión Latine en los años veinte. Pese a que había presentado al agregado de Prensa de la Embajada española en París, Antonio Zuloaga, una declaración-retractación en 1940 (como ya indicamos en páginas precedentes), de forma misteriosa la misma se había perdido, por lo que su proceso siguió adelante. Es sorprendente que un documento tan trascendente desapareciese del Archivo de la VSEP, máxime cuando se elaboraron copias del mismo para el entonces director General de Prensa, Pablo Merry del Val, para el jefe de Prensa Extranjera, Antonio Reverte, y, más adelante, para el propio subsecretario de Prensa y Propaganda, Antonio Tovar. Más bien parecía un castigo por su "sombría" actividad junto a Solms en Francia, ya que tras la resolución del caso Daranas, además, había sido marginado por las autoridades periodísticas del país, tanto francesas y militares alemanas, así como por la propia colonia española. Sea como fuere, en noviembre de 1943 fue condenado por el delito consumado de Masonería a la pena de doce años y un día de reclusión menor, que fue conmutada por el Consejo de Ministros, el 4 de julio de 1944, a seis días y un año de inhabilitación especial para cargos públicos y de confianza ${ }^{39}$.

\footnotetext{
${ }^{37}$ AGA, Cultura, caja 233. "Escrito de Mariano Daranas al Sr. D. Felipe de Solms Davids", 23 de ocutbre de 1942.

${ }^{38}$ AGA, Cultura, caja 233. "Escrito de Felipe de Solms al Delegado Nacional de Prensa", 9 de noviembre de 1942.

${ }^{39} \mathrm{CDMH}, \mathrm{TERMC}$, sumario n. 454․ "Sentencia de la causa instruida contra Bartolomé Calderón Fonte", 8 de noviembre de 1943.
} 


\section{A modo de conclusión}

Felipe de Solms y Bartolomé Calderón Fonte fueron los grandes perjudicados de su choque con Mariano Daranas. La decisión del Tribunal de Honor de París así como los interrogatorios que sufrieron en España por parte de la Delegación Nacional de Prensa nos dejaron un retrato en el que la acusación de "judío" o "masón" parecía clara y rotunda. Nada más lejos de la realidad. Documentación previa y posterior (silenciada en estos procesos por sus superiores), custodiada en las carpetas del Ministerio de Exteriores y Cultura, presentaban un cuadro en el que faltaban muchas pinceladas. Calderón Fonte fue acusado y condenado por masón, dando por inválida (ya que se había "traspapelado") su declaración de retractación ante el agregado de Prensa, Antonio Zuloaga, uno de los más firmes opositores a la figura del falangista Federico Velilla, a su vez criticado por el propio Solms. Podría interpretarse que Calderón no contaba con el beneplácito de Falange en París, lo que le pudo perjudicar en ese litigio. Sin embargo, no era así. En 1939, el Jefe Local de París y Secretario Provincial de FET y de las JONS, Aurelio Pérez Rumbao, lo definía "como un militante que desde el primer momento ha defendido brillantemente nuestra Causa con su pluma y su talento" ${ }^{40}$. No había dudas sobre su pertenencia pasada a una logia masónica francesa, pero quedaron silenciadas las decenas de artículos -ya fuese con su verdadero nombre o con el pseudónimo de Juan Pedro Luna- aparecidos en La Vanguardia, entre 1940 y 1942, arremetiendo contra cualquier aspecto relacionado con la masonería y la política gala (DOMíNGUEZ, 2009: 326). Precisamente, fue esta actitud -en ocasiones excesivamente crítica y vehemente- la que jugó con mayor peso en su contra. Sentencias como que los periódicos de París, excepto Le Matin o Le Patit Parisien, "dan la impresión de Prensa pueblerina" ${ }^{41}$, o que "Francia, sin distinción de zonas, no ha despertado del letargo en que la sumió el armisticio" ${ }^{42}$, no fueron del gusto del gremio de periodistas galos, ni de las autoridades de ocupación germanas, ni de Vichy y, por supuesto, de la VSEP, que no querían ningún tipo de altercado con sus socios extranjeros. Este aseveración se refuerza con el hecho de que en octubre de 1941 fue interrogado por las fuerzas de seguridad galas por usar indebidamente el pasaporte español ${ }^{43}$. Por tanto, parece deducible que en caso de duda a la hora de posicionarse en la disputa que protagonizó, Francia y los dirigentes del Tercer Reich, apoyasen más decididamente la causa de Daranas, con las nefastas consecuencias futuras que ello tendría.

\footnotetext{
40 AGA, Presidencia, Registro Oficial de Periodistas, caja 13912, expediente 2004. "Escrito de Aurelio Pérez Rumbao", 20 de abril de 1939.

${ }^{41}$ La Vanguardia, "El ocaso de la Prensa", Bartolomé Calderón Fonte, 25 de febrero de 1942.

42 La Vanguardia, "Aniversario romántico", Bartolomé Calderón Fonte, 18 de diciembre de 1941.

43 AGA, Presidencia, Registro Oficial de Periodistas, caja 13912, expediente 2004. "Escrito de Aurelio Pérez Rumbao", 20 de abril de 1939.
} 
Con respecto a Solms, durante todo el proceso que debía dirimir su honor se vertieron infinidad de falsedades que no se corrobaron, sino que se convirtieron en verdades irrefutables. Se dijo que nunca había combatido en la Guerra Civil española, resultado de una maniobra evasiva "muy judía" (véanse páginas anteriores). En 1943, apelando a excelentes contactos dentro del Ejército -y por tanto, rivales en las luchas de poder con el Partido- se explicó que "vino voluntariamente a España, a presentarse en las Filas Nacionales, alistándose como soldado en el Tercer Regimiento de Artilleria Pesada, pasando varios meses en el frente...", demostrando "valor, inteligencia y obediencia ciega". Incluso, José López Barrón, Teniente Coronel del Estado Mayor y Secretario General de la Dirección General de Seguridad expresó que "es persona de buena conducta, así como de ideas derechistas, católico, y totalmente afecto a nuestro Glorioso Movimiento Nacional". Y lo que era más importante, "no figurando como de origen judío"44. A tenor de lo analizado a lo largo de esta investigación, consideramos que Solms y Calderón Fonte cayeron en desgracia ante la Delegación Nacional de Prensa y los jerarcas franquistas por haberse posicionado en el pasado a determinados líderes falangistas en Francia (caso de Velilla), así como a ciertos sectores de la colonia española (que los consideraban como simples "galos", recién llegados que querían beneficiarse de las "oportunidades" que ofrecía la "Nueva España" en el plano propagandístico), encabezados por Mariano Daranas. Con una posición claramente en auge, como lo probaban las colaboraciones de Solms con la Embajada alemana en París, aprovecharon un falso rumor para generar un conflicto entre ambos sectores. Además, en el caso de Calderón Fonte, sus crónicas y matrimonio con una francesa de origen judío (al igual que Solms), le generaron la animadversión de los propagandistas de Vichy. Este tipo de incidentes son de gran interés para el historiador, pues prueban que detrás del manto de unidad que quería proyectar la España franquista en el exterior, asomaban multitud de matices e intereses diferentes ( $y$ contrapuestos) que daban al traste con este panorama monocolor. En esta particular guerra de posicionamientos políticos, cualquier argumentación valía, en especial si se podía acusar o retratar al adversario -incluso si lucía la misma camisa- de masón o judío, en unos años donde estos clichés eran signos de alianza con los defenestrados "rojos".

\section{Referencias bibliográficas}

\footnotetext{
44 AGA, Presidencia, Servicio Nacional de Excombatientes, caja 4068, expediente 12474, "Felipe de Solms".
} 
ANDRÉS GALLEGO, J., PAZOS, A.Ma y ANDRÉS URTASÚN, Mạ de (2011): “Dos Españas (y, además, asimétricas) para una sola Exposición (París, 1937)", en Moreno Cantano, A.C. (coord.), El ocaso de la verdad. Propaganda y prensa exterior en la España franquista (1936-1945), Gijón, Editorial Trea, pp. 41-72.

BERMEJO, B. (1996): "La Falange española en Francia”, en Cuesta, J. y Bermejo, B. (coords.), Emigración y exilio. Españoles en Francia, 1936-1946, Madrid, Eudema, pp. 228-242.

CAZORLA, A. (2000): Las políticas de la victoria. La consolidación del nuevo Estado franquista (1938-1953), Madrid, Marcial Pons Historia.

CULLA, J.B. (2005): “Ni tan jóvenes ni tan bárbaros: las juventudes en el republicanismo lerrouxista barcelonés", Ayer. Revista de Historia Contemporánea, n.o 59, pp. 5167.

D'ORS, E. (2000): Estudios sobre Manuel Machado, Sevilla, Editorial Renacimiento.

DOMÍNGUEZ ARRIBAS, J. (2009): El enemigo judeo-masónico en la propaganda franquista (1936-1945), Madrid, Marcial Pons Historia.

FESTORAZZI, R. (2009): I/ segreto del conformista. Vita di Giacomo Antonini, I'uomo che spiò Carlo Rosselli ispirando Moravia, Soveria Mannelli, Rubbettino Editore.

GONZÁLEZ CALLEJA, E. (1990): “La prensa falangista y la prensa del Movimiento y del Estado: consideraciones sobre su origen y desarrollo", en Lara, T. de (dir), Comunicación, cultura y política durante la II República y la Guerra Civil, t. II, Universidad del País Vasco.

LÓPEZ ZAPICO, M.A. (2013): "Much ado about nothing. El servicio de falange exterior en Estados Unidos", en Moreno Cantano, A.C. (coord.), Cruzados de Franco. Propaganda y diplomacia en tiempos de guerra (1936-1945), Gijón, Editorial Trea, pp. 211-239.

MASSOT I MUNTANER, J. (1998): Tres escriptors davant la Guerra Civil. Georges Bernanos, Joan Estelrich i Llorenç Villalonga, Barcelona, Publicacions de I'Abadia de Montserrat.

MORENO CANTANO, A.C. (2007): "Delegaciones y oficinas de prensa y propaganda españolas en el extranjero durante el primer franquismo: el caso francés (19361942)", Studia Historica. Historia Contemporánea, n.․2 25, 2007, pp. 265-301.

MORENO CANTANO, A.C. (2016): El control de la prensa extranjera en España durante el primer franquismo (1936-1945), Sarrión (Teruel), Muñoz Moya Editores. 
RIQUER, B. De (1997): El último Cambó, 1936-1947. La tentación autoritaria, Barcelona, Grijalbo.

SUÁREZ-ZULOAGA, I. (2012): “Antonio Zuloaga Dethomas: una vida entre España y Francia", en Moreno Cantano, A.C. (coord.), Propagandistas y diplomáticos al servicio de Franco, Gijón, Editorial Trea, pp. 121-148.

THOMÀS, J. M.a (2001): La Falange de Franco. Fascismo y fascistización en el régimen franquista (1937-1945), Barcelona, Plaza \& Janes. 